\title{
Neither ivory towers nor corporate universities: moving public universities beyond the "mode 2" logic
}

\author{
N Ravjee \\ University of Stellenbosch
}

\begin{abstract}
This article investigates the tensions in the "mode 2" thesis, which suggests the emergence of new, global trends in the production and dissemination of knowledge. I explain its influence in recent South African higher education policy debates and research practices by referring to competing readings of "mode 2 ", which have allowed it to feed simultaneously into both liberal and critical discourses on higher education transformation in South Africa. Clear tensions emerge from the limitations of "mode 2" in speaking to existing inequalities and in informing non-corporate models of institutional transformation.
\end{abstract}

\section{INTRODUCTION}

\begin{abstract}
A recent publication titled The new production of knowledge: the dynamics of science and research in contemporary societies (Gibbons et al 1994) suggesting the emergence of new, global trends in the production and dissemination of knowledge, has strongly influenced South African higher education and science policy debates since 1995. Its thesis is simply that changes are occurring in how western industrialised countries produce, organise and disseminate knowledge, and these changes have implications for how national science systems and universities are managed, not only in the west, but also globally.
\end{abstract}

Adopting a Marxist metaphor, "mode of production", and applying it to knowledge, the authors suggest that specific global changes - increased demands for specialized knowledge and increased access to higher education since the 1960s - are driving universities away from what they call "mode 1 science" (discipline-based, elitist, ivory-tower models of university research, etc) towards "mode 2 knowledge production" (context of application transdisciplinary research, increased industrialization of science, broader participation, organizational diversity, etc). They define this new mode as a socially distributed knowledge production system involving, on the one hand, people/institutions/countries with access to new technological and other resources. On the other hand, they assert that this emerging way of producing knowledge will not change current levels of unequal participation in research (conducting research, deciding on research agendas, funding research, using results): "Even as Mode 2 knowledge production is more globally dispersed, its economic benefits will be disproportionately reappropriated by rich countries and those who are able to participate" (Gibbons et al 1994:166).

This article briefly summarises and investigates the tensions in the "mode 2" thesis. I explain its influence in recent South African higher education policy debates and research practices by referring to competing readings of "mode 2", which I argue, have allowed it to feed simultaneously into both liberal and critical discourses on higher education transformation. The resulting blurred meanings about specific concepts (such as reflexivity, relevant knowledge, new partnerships, etc), point to the limitations of "mode 2" in speaking to existing inequalities and in informing non-corporate models of institutional transformation.

\section{THE APPEARANCE OF "MODE 2" IN SOUTH AFRICAN HIGHER EDUCATION DEBATES}

The "mode 2" thesis has clearly influenced recent higher education debates in South Africa to the level of foremost policy documents. Documentary evidence in support of the interesting, yet puzzling and often uncritical, policy preoccupation with "mode 2" begins with papers commissioned around the theme of knowledge by the National Council of Higher Education in 1995. And thereafter, in subsequent policy documents such as the report of the National Commission on Higher Education (NCHE 1996), the White Paper on Science and Technology (1996), the Green paper on Higher Education Transformation 
(1996) and the White Paper on Higher Education (1997). The concept of "mode 2" knowledge production has since been a focus of numerous local seminars, workshops and journal articles (Rip 1998; Hay 2000), policy research (Kraak 2000; Cloete \& Bunting 2000), and research projects (Kraak \& Watters 1995; Subotzky, Mouton \& Rip 1998). It is possible that subsequent presentations by Michael Gibbons (1998a, 1998c, 2000) and Peter Scott (1997) to South African audiences may have contributed to the idea of "mode 2" as something more than an analytical category used to make sense of empirical data from a given context. This reification is evident in university-level research policy documents (Duvenage 1998; Verkleij 1999), and therefore unsurprisingly may emerge in currently evolving research practices at the institutional level.

The local literature is divided on the question of what positive ways the notion of "mode 2" can inform higher education policies in South Africa. The diverse interpretations suggest that it has fed simultaneously into opposing views on knowledge and higher education transformation. At one end of the spectrum is a view of "mode 2" as a locally useful model representing a movement away from elitist, unitary and "epistemologically reactionary" forms of knowledge production towards more democratic and plural forms (Kraak 1996). This interpretation views as a strength the challenge "mode 2" presents to the dominance of university structures over knowledge production, and the idea of a relevant science through new partnerships with "key societal stakeholders." At the other end of the spectrum is a concern with the ways in which local debates about "mode 2", by focusing attention on "the globalisation of knowledge, the competitive and trade value of knowledge as a commercial product, and the significance of nonuniversity settings in knowledge production" (Jansen 1998:113), have failed to deal with the curriculum politics and inherited colonial institutional cultures in higher education.

Most local studies fall somewhere along the continuum between these two positions. Many theorists have embraced different aspects of the "mode 2" thesis (and to different degrees) to understand the South African experience, finding, as Rip (2000:60) suggests, the label "mode 2" useful to name and to come to terms with changing research practices. At the same time, reliance on the label may also function to lock-in, and therefore narrow and limit, the "increasing variety of, and a new openness to, ways of knowledge production" (Rip 1998:76-79) by naming them under the banner of "mode 2" knowledge production. This dilemma is evident, for example, in debates about the meanings of accepting different aspects of the "mode 2" thesis (Kraak 1995: Subotzky 1998), and on questions about assessing the quality and funding of transdisciplinary research (Bawa 1997; Mouton 1996; Muller 1996, 1999). An interesting interpretation of "mode 2 ", recognizing its pro-market orientation, interprets it in ways other than as an orientation towards the market. It begins with this question: what ideas about the role of higher education and development emerge if we think about knowledge production and higher education, not in relation to commercial markets, but social needs? (Subotzky 1998, 1999). Finally, a cautious response (Mouton 1996; Bawa 1997) stops short of rejecting the usefulness of "mode 2 " in understanding higher education change, and seeks empirical evidence to determine whether the described changes are indeed occurring in South Africa.

A broad overview of South African theorizing about "mode 2" suggests, first, a predominantly uncritical stance towards the notion of "mode 2" itself. Yet existing critiques advise against too hastily embracing it to inform higher education policy and practice, claiming that the changes described are neither unique nor historically unprecedented (Weingart 1997; Shin 1999), but describe increasing market values and other corporate influences in higher education and so function to shift attention away from how power-knowledge regimes function in higher education and towards the commodification of knowledge (Fuller 1995; Jansen 1998). Second, the distinction between "mode 2" as an analytical tool constructed to make sense of empirical data from a given context, and "mode 2 " as a model for change, is blurred in many of the studies, and in so far as the authors predict future global scenarios, it is increasingly viewed as a model. While this may not be the intention of Gibbons et al, the distinction between their observations and their prescriptions is ambiguous in the South African debates. Third, in privileging different aspects of the 1994 text, the local studies represent different, sometimes conflicting readings of "mode 2 ", leading to blurred meanings of central ideas (eg relevant knowledge, heterogeneity, reflexivity, accountability, social distribution, etc) in policy debates. Let's examine two possible ways of approaching "mode 2", and consider how they may function to blur the meanings of key concepts in higher education.

\section{BLURRED MEANINGS}

This section follows two threads of ideas that run through the texts by Gibbons (1994, 1997, 1998a, 1998b, 1998c, 2000) and Scott (1997, 1998). We may think about each thread as clusters of ideas representing competing readings of "mode 2", and feeding simultaneously into liberal and critical discourses on higher education transformation in South Africa. While both interpretations challenge the ivory tower image of western universities, they evoke different models of higher education transformation. The first - let's call it "'mode 2' as a market metaphor" - privileges the role of the market in shaping and 
regulating higher education, while the second which we may label ' 'mode 2' as a social relevance paradigm" - views educational change in relation to its broader contexts (social, economic, political, cultural, historical, etc) and emphasizes the role of non-market values such as reflexivity and accountability.

\section{"Mode 2" as a market metaphor}

It's authors locate the emergence of "mode 2 " in the supply-demand forces of social and commercial markets (increasing "supply" of graduates able to conduct independent research; increasing "demands" for specialist knowledge from commerce and civil society), leading to a more socially distributed knowledge production system - which they call "mode 2" in which problems are set outside of disciplinary frameworks in contexts of application, and research is conducted in diverse transdisciplinary teams, which are transient and not institutionalized within universities.

The starting point of their analysis is the global economy. They view the central challenge of our times as being able to produce knowledge for economic competitiveness in the persisting global division of labour: "The future shape of knowledge production has to be seen in the context of the changing nature of the global economy and of ever new configurations of knowledge. In this, information technology systems clearly play a crucial role. At the same time, the notions of competence become redefined and boundaries of organisations tend to become blurred. Problem solvers, problem identifiers and strategic brokers move back and forth. Knowledge resources are held in different organisations and can be shifted between environments which are at one moment competitive and at another collaborative" (Gibbons et al 1994:48).

Following Reich (1991), Gibbons et al view "the search for non-imitable, knowledge-dependent innovations" as the driving force behind the manufacturing industries largely responsible for capitalist economic growth in industrialised countries. This has occurred, they explain, through the "industrialisation of science", involving increased partnerships between academia and industry and the permeation of industrial management practices into universities (Gibbons et al 1994:52-62). They identify this new techno-economic paradigm as the source of the "radical shift in the structure of institutions to meet the new requirements of knowledge production and distribution" (1994:118), and outline implications for national systems of innovation and for universities. They view changes in universities (towards corporate management styles, technology interchange, transdisciplinarity, etc) as having their basis in the dominant techno-economic paradigm, and specifically in the new knowledge industries.

Building on their market metaphor, the authors compare universities to supply machines, reservoirs of "competencies trained in the latest skills and techniques" required by industry: "Industry has a vested interest in keeping the reservoir full and flowing. So far, it has been able to achieve this at little cost to itself. ... This transformation is one of the most far-reaching that we have described because it involves drawing the universities into the heart of the commercial process. The universities are no longer the remote source and wellspring of invention and creativity but are part of the problem solving, problem identification and strategic brokering that characterize the knowledge industries" (Gibbons et al 1994:86).

For public universities, they predict/observe (the distinction is often unclear, as I discuss below) an increase in corporate management styles, more flexible organizational structures, smaller core faculties, rewarding research over teaching, increased partnerships with industry, multiple sources of funding, outsourcing of non-core functions, a greater role in economic production processes, formation of spinoff companies, etc (Gibbons 1998:12-13). The strength of universities will lie in the small research teams that are opportunistic in searching for research funding and niche specialisations. Curricula and funding will follow market mechanisms, dominated by skills training for the economy and increases in targeted approaches to funding with corresponding reductions in block grant funding (Gibbons et al 1994:79). Universities able to survive this changed global environment, the authors suggest, will be those capable of aligning themselves as efficiently run corporate universities involved in selling knowledge as a commodity to diverse social and economic markets.

The distinction between what the proponents of "mode 2" "observe" and what they "predict" as inevitable global trends is ambiguous, and feeds into recent South African national policy shifts towards greater private sector involvement in the provision of public services. Current changes at UCT and Wits provide interesting cases of the effects of this ambiguity (in the policy preoccupation with "mode 2 " as a model) on university changes. For example, Barchiesi's (2000) study of the managerial rhetoric and corporate practices associated with "Wits 2001". the transformation plan for the University of Witwatersrand, aptly captures the dilemmas of viewing education and other social services as commodities and citizens as primarily consumers. With regard to students, one scenario may be that universities will increasingly churn out technicians for the economy, but no democrats. Let's turn to another possible meaning of "mode 2 ". 


\section{"Mode 2" as a social relevance paradigm}

Following another cluster of ideas embedded somewhat weakly in the 1994 and subsequent studies by Gibbons et al, we find a description of current changes in western universities as challenging the exclusionary and elitist Newtonian model of disciplinary experts in ivory towers. The following quotations from the 1994 study neatly capture their mode 1 - mode 2 dichotomy:

... the term Mode 1 refers to a form of knowledge production - a complex of ideas, methods, values, norms - that has grown up to control the diffusion of the Newtonian model to more and more fields of enquiry and ensure its compliance with what is considered sound scientific practice. Mode 1 is meant to summarise in a single phrase the cognitive and social norms which must be followed in the production, legitimation and diffusion of knowledge of this kind. For many, Mode 1 is identical with what is meant by science. Its cognitive and social norms determine what shall count as significant problems, who shall be allowed to practice science and what constitutes good science. Forms of practice which adhere to these rules are by definition scientific while those that violate them are not. (Gibbons et al 1994:3)

Our view is that while Mode 2 may not be replacing Mode 1. Mode 2 is different from Mode 1 - in nearly every respect. The new mode operates within a context of application in that problems are not set within a disciplinary framework. It is transdisciplinary rather than mono- or multi-disciplinary. It is carried out in non-hierarchical, heterogeneously organised forms which are essentially transient. It is not being institutionalised primarily within university structures. Mode 2 involves the close interaction of many actors throughout the process of knowledge production and this means that knowledge production is becoming more and more socially accountable. One consequence of these changes is that Mode 2 makes use of a wider range of criteria in judging quality control. Overall, the process of knowledge production is becoming more reflexive and affects at the deepest levels what shall count as "good science" (Gibbons et al 1994:vii)

The language of "mode 2" describes changes in terms of relevance to social goals: non-hierarchical, socially distributed, reflexive, heterogeneously organized, socially accountable, etc. This view supports "a socially-engaged and socially-distributed science" (Scott 1997:38) capable of addressing tensions between "metropolitan" knowledge traditions (with their claims of objectivity and universality) and "local" knowledge traditions (Scott 1997:20). For example, the notion of transdisciplinarity, which is also central to their analysis of industry led research trends, challenges both the disciplinary hierarchies introduced by the modern western universities, and the idea of science as an autonomous, neutral, ahistorical system developing through its own internal dynamics. It also provides a basis from which to construct alternative models of socially redistributed knowledge, and to deconstruct persisting dichotomies (eg western science versus indigenous knowledge) about knowledge. The following quotation is instructive: "Science does not stand outside of society dispensing its gifts of knowledge and wisdom; neither is it an autonomous enclave that is now being crushed under the weight of narrowly commercial or political interests. On the contrary, science has always both shaped and been shaped by society in a process that is as complex as it is variegated; it is not static but dynamic" (Gibbons et al 1994:22).

The puzzling point is that while both interpretations appear in the South African policy literature and documents, the second framing of "mode 2" as a social relevance paradigm rests uncomfortably in tension with the first, and is not a dominant focus in the major thesis, in which the analysis of universitycivil society relations is thin, and restricted to a very brief discussion of what Gibbons et al term "social markets" for specialised knowledge. They suggest that scientific controversies, often based on public demands for accountability (eg pollution, asbestos mining, tobacco products, recycling, etc), or access to technology-based resources (eg water, electricity, housing, medical drugs, etc), enhance the markets for private firms to develop new research agendas and products. While Gibbons et al assert that this new way of producing knowledge is not entirely marketdriven - claiming that it "is about more than just economic benefit" (1994:15) - their analysis does not deal extensively with the demands for new knowledge from these kinds of "social markets". Instead, they focus primarily on the demands for specialised knowledge from global commercial markets, where the competitive advantage of a firm depends on its capacity to configure and use knowledge.

Their privileging of dominant economic against social paradigms permits little space for mechanisms of redistribution to be seriously considered. For example, how will support for university-industry partnerships stimulate sustainable development in historically neglected areas? How will these partnerships be geared towards social needs? (Williams 1999:63). A disturbing question arises: Will "mode 2" knowledge production be used locally to justify the continuation, and expansion to other fields, of specific practices (such as scientists designing machinery, industrialization and scientific standardization, patent reform, intellectual property rights, industry-university research partnerships), which since the $19^{\text {th }}$ century (Nobel 1977) have drawn natural scientists in western industrialized countries into the production 
processes of industry? What would interventions designed to build the capacity of individuals, institutions and regions to design, fund, conduct and use the findings of research look like in the "mode 2" logic?

These tensions are reflected in the blurred meanings of central higher education concepts (eg reflexivity, relevant knowledge, social accountability, cooperation, etc), and their redefinitions in terms of the new policy language. To illustrate this point, consider the idea of "aloofness from social context". Both interpretations challenge the ivory tower image of the traditional western university, but in different ways, and suggest different answers to the question: what counts as relevant knowledge, and for whom? On the first reading ("mode 2" as a market metaphor), challenging universities' traditional claims of aloofness may function to break down protective university mechanisms against the intrusion of corporate interests in higher education. The other meaning of challenging public universities' aloofness to social context ("mode 2" as a social relevance paradigm) focuses on increasing partnerships and cooperation with civil society in non-hierarchical and reflexive ways. So the meaning of "what counts as relevant knowledge" in policy debates is blurred, and it is this blurring that allows the idea of mode 2 to feed into competing discourses, yet in the process being redefined in terms of the dominant technical-rational discourse.

The interesting point is that these meanings are blurred in the contradictory language of "mode 2" which suggests, on the one hand, that moving away from the idea of "pure science" will allow universities in the Third World to produce research that is relevant to development (Gibbons 1998:55), yet accepting on the other hand, the inability of "mode 2" to address existing inequalities (Gibbons et al 1994:166). This tension appears in various new institutional practices and policies. For example, many current practices at South African universities - eg continuing financial exclusion of students, increases in contract staff, outsourcing of non-core functions, new industryuniversity partnerships, intellectual property offices, downsizing, mergers, "publish-or-perish" culture, management rhetoric, etc - may all be understood in a logic that ranks the value of educational activities on their market potential.

At the national level, this tension is evident in contradictory state policies, which on the one hand, aim to change dominant social and economic relations, and on the other, support economic growth and social services provision through privatization. Yet, this challenge is neither new nor unique to the South African experience. As Carnoy and Samoff (1990) have shown, this tension is central to societies in transition, where state-driven social development often conflicts with production relations in the private economy. Neither is this tension unique to societies in transition, as current disputes about the provision of public services through public-private partnerships in western countries show. The idea of moving public universities beyond the "mode 2" logic re-situates the "relevance question" to mean more than relevance to market needs by including wider questions of relevance to individual and broad social transformation.

\section{CONCLUSION}

Finally, the tensions and ambiguities in the notion of "mode 2 " raise numerous questions requiring further debate. First, the mode 2 thesis claims to describe changes in western industrialized countries. Its authors present it as a model for other countries to follow in a global market structured into unequal blocks of wants/needs. How relevant is the "mode 2" thesis to SA, which has certain unique features - a fragmented colonial history of a society deeply divided by issues of class, race and gender, continuing unequal material distribution, a new political system, a country entering a global market divided into cores and peripheries, etc? If we want to understand how this broad historical context shapes the curriculum politics of knowledge production, we may also then ask, how are issues of knowledge and power theorized within the notion of "mode 2", if at all? The question of relevance to the SA condition has not been widely discussed.

Second, what are the consequences of ignoring a central contradiction in the notion of socially distributed knowledge: that the movement towards socially distributed knowledge, as conceived by Gibbons et al, is likely to contribute to increasing inequalities. How useful is a model of change that does not speak to existing inequalities? Finally, we require more debate about the parallel idea that South African universities able to survive this changed environment will be those capable of aligning themselves as efficiently run "market universities" involved in selling knowledge as a commodity to diverse social and economic markets. Will this type of ahistorical corporate institutional model be able to be reflexive in ways that counter the intrusion of market values and corporate interests into the governance structures, institutional cultures and curricula of public universities? 


\section{REFERENCES}

Barchiesi, Franco 2000. South Africa: the lean and mean university. Tertiary education restructuring and the rise of managerialism. Submitted to Southern Africa Report.

Bawa, A C 1997. Knowledge production and curriculum strategies in South Africa, in Cloete N et al (eds) Knowledge, identity and curriculum transformation in Africa. Cape Town: Maskew Miller Longman.

Carnoy, M \& Samoff, J 1990. Education and social transition in the Third World. Princeton, New Jersey: Princeton University Press.

Kraak, Andre (ed) 2000. Changing modes. New knowledge production and its implications for higher education in South Africa. Pretoria: Human Science Research Council.

Cloete, Nico \& Bunting, Ian 2000. Is higher education in South Africa moving towards national transformation goals? Pretoria: CHET.

Department of Arts, Culture, Science and Technology 1996. White Paper on Science and Technology. Preparing for the $21^{\text {st }}$ Century. Pretoria.

Department of Education 1996. Green Paper on Higher Education Transformation. Pretoria.

Department of Education 1997. Education White Paper 3 - A Programme for the Transformation of Higher Education. Pretoria.

Duvenage, Pieter 1998. A strategic research plan for the humanities and the social sciences at the University of the North. University of the North.

Fuller, Steve 1995. Review essay. Is there life after sociological theory after the sociology of scientific knowledge. Sociology 29(1):159-166.

Gibbons, Michael, Limoges, Camille, Nowotny, Helga, Schwartzman, Siman, Scott, Peter \& Trow, Martin 1994. The new production of knowledge. The dynamics of science and research in contemporary societies. London: Sage.

Gibbons, Michael 2000. Universities and the production of new knowledge: some policy implications for government, in Kraak. Andre (ed) Changing modes. New knowledge production and its implications for higher education in South Africa. Pretoria: Human Science Research Council.

Gibbons, Michael 1998a. New dimensions of international co-operation in higher education: rethinking relevance and institutional location of knowledge generation in the South. NORRAG News No 23, Oct, edited by Kenneth King. Edinburgh: Scotland.

Gibbons, Michael 1998b. A commonwealth perspective on the globalization of higher education, in Scott, Peter (ed) The globalization of higher education. Philadelphia, USA: The Society for Research into Higher Education \& Open University Press.

Gibbons, Michael 1998c. Higher education and relevance in the $21^{\text {st }}$ Century. Presented at the UNESCO World Conference on Higher Education. Paris. 5-9 October 1998.

Gibbons, Michael 1997. The translation of societal needs into research agendas, in Barre, Remi, Gibbons, Michael, Maddox, John, \& Papon, Pierre (eds) Science in tomorrow's Europe. Paris: Economica International.

Jansen, Jonathan D 1998. But our natives are different! Race, knowledge and power in the academy. Social Dynamics 24(2):106-116.

Kraak, Andre \& Watters, Kathy 1995. Investigating knowledge production: a Western Cape higher education case study. Paper Commisioned by Taskgroup Two of the National Commission on Higher Education of South Africa.

Kraak, Andre 1997. Globalisation, changes in knowledge production, and the transformation of higher education, in Cloete, Nico et al (eds) Knowledge, identity and curriculum transformation in Africa. Cape Town: Maskew Miller Longman.

Kraak, Andre 1996. Globalisation, the learning society and the case for a unified system of higher education in South Africa. Presented at the New Modes of Knowledge Production seminar. University of Stellenbosch.

Mouton, Johann 1996. New modes of knowledge production: the Gibbons thesis. Presented at the New Modes of Knowledge Production seminar. University of Stellenbosch.

Muller, Johan 1999. What knowledge is of most worth for the millennium citizen? Presented at the workshop titled New Knowledge Production - Interrogating the Gibbons Thesis from the South African Perspective. Education Policy Unit, University of Western Cape. 27 July 1999.

Muller, Johan 1998. Editorial introduction. The curriculum debate at UCT. Social Dynamics 24(2).

Muller, Johan 1996. Higher education and new knowledge production. Presented at the New Modes of Knowledge Production seminar. University of Stellenbosch.

National Commision on Higher Education 1996. A framework for transformation. Final report of the National Commission on Higher Education. Pretoria: NCHE. 
Noble, David 1977. America by design: science, technology, and the rise of corporate capitalism. New York: Alfred A. Knopf.

Ravjee, Neetha 1999. "Modes" of knowledge production and higher education in South Africa: a critical review of the literature. Paper presented at the workshop titled New Knowledge Production - Interrogating the Gibbons Thesis from the South African Perspective. Education Policy Unit, University of Western Cape. 27 July 1999.

Reich, R 1991. The work of nations: preparing ourselves for $21^{\text {st }}$ Century capitalism. London: Simon and Schuster.

Rip, Arie 2000. Fashions, lock-ins and the heterogeneity of knowledge production, in Kraak, Andre (ed) Changing modes. New knowledge production and its implications for higher education in South Africa. Pretoria: Human Science Research Council.

Rip. Arie 1998. Postgraduate training and research in South Africa: an international perspective. SAUVCA Publication Series 98(3):69-80.

Scott, Peter 1997. Changes in knowledge production and dissemination in the context of global competition, in Cloete, Nico et al (eds) Knowledge, identity and curriculum transformation in Africa. Cape Town: Maskew Miller Longman.

Shinn, Terry 1999. Change or mutation? Reflections on the foundations of contemporary science. Social Science Information 38(1):149-176.

Subotzky, George 1999. Complementing the marketization of higher education: knowledge production for social development in community-higher education partnerships. Paper presented at the workshop titled New Knowledge Production - Interrogating the Gibbons Thesis from the South African Perspective. Education Policy Unit, University of Western Cape. 27 July 1999.

Subotzky, George 1998. Alternatives to the entrepreneurial university: new modes of knowledge production in community service programs. Presented at the ASHE Conference, Miami, Nov 1998.

Subotzky, George, Mouton, Johann \& Rip, Arie 1998. SANPAD funded research project titled "Enhancing the Contribution of Higher Education to Development: Investigating modes of knowledge production and developing an appropriate research capacity building model."

Scott, Peter (ed) 1998. The globalization of higher education. Philadelphia, USA: The Society for Research into Higher Education \& Open University Press.

Verkleij, Adrian C L 1999. An approach for sustainable quality promotion of postgraduate education and research. Center for Higher Education Policy Studies (CHELPS), University of Twente, The Netherlands. Report prepared for $\mathrm{PU}$ for $\mathrm{CHE}$.

Weingart, Peter 1997. From "finalization" to "mode 2": old wine in new bottles? Social Science Information $36(4): 591-613$.

Williams, John J 1999. World Bank scenarios. Why they should be rejected. South African Labour Bulletin 23(1) Feb 1999. 